\section{The usefulness of serum delta neutrophil index for differentiating bacterial and viral meningitis in the emergency department}

\author{
Joon Woo Lee', Chan Ik Park², Hyung II Kim', Oh Hyun Kim', \\ Kyoung Chul Cha', Hyun Kim ', Kang Hyun Lee', Sung Oh Hwang', \\ Yong Sung Cha ${ }^{1}$
}

'Department of Emergency Medicine, Yonsei University Wonju College of Medicine, Wonju, Korea ${ }^{2}$ Department of Neurology, Yonsei University Wonju College of Medicine, Wonju, Korea

Objective When managing patients with acute meningitis in an emergency department (ED), early diagnosis of the type of infection (bacterial or viral) considerably affects the clinical course and treatment because of the high mortality and morbidity associated with bacterial meningitis (BM). The serum delta neutrophil index (DNI), a new inflammatory marker, reflects the fraction of circulating immature granulocytes and is elevated in cases of bacterial infection. The objective of this study was to evaluate whether serum DNI can be used to differentiate between BM and viral meningitis (VM) in the ED.

Methods This retrospective, observational study included 104 consecutive patients (aged $>18$ years) diagnosed with acute meningitis from January 2012 to November 2014 in a regional emergency center. White blood cell and neutrophil counts, C-reactive protein level, and DNI were evaluated regarding their usefulness for differentiating BM and VM.

Results Serum DNI was not significantly higher in the BM group $(n=12)$ than in the VM group ( $n=92$ ) (0 [interquartile range, $0 \%$ to $2.73 \%$ ] vs. 0 [interquartile range, 0 to $0 \%$ ], $P=0.057$ ). However, the white blood cell count and C-reactive protein level were statistically higher in the BM group $(P=0.034$ and $P=0.026$, respectively). Serum $D N I$ was not found to be a statistically useful differential diagnostic parameter (area under the curve, 0.628; 95\% confidence interval, 0.438 to 0.818 ).

Conclusion Currently, there is no evidence that the serum DNI aids in differentiating acute BM from acute VM in the ED.

Keywords Biochemical markers; Meningitis; Delta neutrophil index
elSSN: 2383-4625

Received: 27 February 2016

Revised: 10 April 2016

Accepted: 14 April 2016

Correspondence to: Yong Sung Cha Department of Emergency Medicine, Yonsei University Wonju College of Medicine, 1 Yeonsedae-gil, Wonju 26493, Korea

E-mail: zza96@hanmail.net

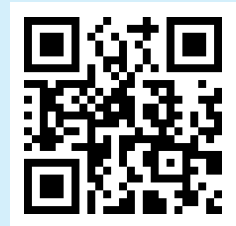

How to cite this article: Lee JW, Park Cl, Kim HI, Kim OH, Cha KC, Kim H, Lee KH, Hwang SO, Cha YS. The usefulness of serum delta neutrophil index for differentiating bacterial and viral meningitis in the emergency department. Clin Exp Emerg Med 2016;3(2):95-99.

This is an Open Access article distributed under the terms of the Creative Commons Attribution Non-Commercial License (http:// creativecommons.org/licenses/by-nc/4.0/). 


\begin{tabular}{|c|c|}
\hline $\begin{array}{l}\text { Capsule } \\
\text { Summary }\end{array}$ & $\begin{array}{l}\text { What is already known } \\
\text { Serum delta neutrophil index (DNI) values are elevated in the presence of bacterial infection because they reflect circu- } \\
\text { lating immature granulocyte fractions. However, no information is available on the clinical usefulness of serum DNI } \\
\text { with respect to the differentiation between bacterial and viral meningitis in patients with acute meningitis. }\end{array}$ \\
\hline & $\begin{array}{l}\text { What is new in the current study } \\
\text { The median serum DNI in bacterial meningitis was similar to that in viral meningitis. This study provides no evidence to } \\
\text { support the notion that serum DNI aids the differentiation between acute bacterial and acute viral meningitis in the } \\
\text { emergency department. }\end{array}$ \\
\hline
\end{tabular}

\section{INTRODUCTION}

Bacterial meningitis (BM) is an infectious disease of the central nervous system with significant mortality (3\% to $21 \%$ ) and morbidity rates despite antibiotic developments. ${ }^{1,2}$ Therefore, one of the most important decisions made in an emergency department (ED) is whether a patient with acute meningitis has BM or viral meningitis (VM). ${ }^{3}$ However, this differentiation can be challenging for clinicians because symptoms and laboratory assays are often similar and overlap. In practice, before definitive cerebrospinal fluid (CSF) bacterial culture results are available, the majority of patients with acute meningitis are treated with broad-spectrum antibiotics targeting BM, because several days are required to culture BM samples, ${ }^{4}$ and although gram staining and bacterial antigen testing of CSF is highly specific, it is not $100 \%$ sensitive. ${ }^{5-8}$

A number of studies have examined the abilities of different tests to differentiate BM and VM. In particular, serum biomarkers may help determine whether a systemic reaction in acute meningitis is due to a bacterial infection. One new inflammatory marker, serum delta neutrophil index (DNI), provides a measure of the proportion of circulating immature granulocytes, ${ }^{9-11}$ and because infectious conditions are known to increase levels of immature granulocytes, ${ }^{12,13}$ several investigators have examined its ability to predict the development of sepsis. ${ }^{14,15}$ However, no information is available on the clinical usefulness of serum DNI with respect to the differentiation of BM and VM in patients with acute meningitis.

We considered that serum DNI values might be higher in BM than in VM, and thus, this study was undertaken to determine whether serum DNI can be used to differentiate BM and VM in the ED setting.

\section{METHODS}

\section{Study design and data}

This retrospective, observational study included 104 consecutive patients (aged $>18$ years) who received a diagnosis of acute meningitis from January 2012 to November 2014 in a regional emergency center. We enrolled patients at a single urban, tertiary-care hospital with an ED that has an annual visit volume in excess of 43,000 and is staffed 24 hours per day with board-certified emergency physicians. Data were collected by retrospectively reviewing electronic medical records. Data collection was conducted by two emergency physicians blinded to the study objectives and hypothesis, and if there was inter-observer disagreement in the interpretation of clinical data, the two emergency physicians reviewed the case together to come to a conclusion. Training of abstractors was conducted before data collection to reduce bias. This study was approved by the institutional review board of the Wonju College of Medicine, Yonsei University.

Age, sex, mortality, white blood cell (WBC) and neutrophil counts, C-reactive protein (CRP) level, and serum DNI values (obtained in the ED) were investigated. Differential diagnoses of BM were confirmed by microbiological tests of blood and CSF. The diagnostic criteria of BM included the following: positive blood or CSF culture or laboratory findings consistent with BM (CSF WBC $>2,000 / \mu \mathrm{L}$ [relatively specific], CSF protein $>220 \mathrm{mg} / \mathrm{dL}$ [highly predictive], CSF glucose $<34 \mathrm{mg} / \mathrm{dL}$, or CSF to blood glucose ratio $<0.25$ [more strongly predictive]). ${ }^{716}$ The CSF results from all 104 patients were reviewed, and BM was confirmed by a neurologist.

A specific type of automatic cell analyzer (ADVIA 120/2,120; Siemens, Tarrytown, NY, USA) was used for determining DNI. This is a flow cytometry-based hematologic analyzer that uses two independent WBC analysis methods using a myeloperoxidase channel and a lobularity/nuclear density channel. The DNI in leukocyte differentials was calculated using the following formula: $\mathrm{DNI}=$ (the leukocyte subfraction assayed in the myeloperoxidase channel by cytochemical reaction) - (the leukocyte subfraction counted in the nuclear lobularity channel by the reflected light beam). ${ }^{11,17}$

Patients with hematologic abnormalities, tuberculosis, or fungal meningitis and those that had received granulocyte colony- 
Table 1. General characteristics of the study subjects

\begin{tabular}{lc}
\hline Characteristics & Total $(\mathrm{n}=104)$ \\
\hline Age $(\mathrm{yr})$ & $32.0(24.3-44.0)$ \\
Male sex & $52(50.0)$ \\
Differential diagnosis & \\
$\quad$ Viral meningitis & $92(88.5)$ \\
Bacterial meningitis & $12(11.5)$ \\
Mortality & $0(0)$ \\
\hline
\end{tabular}

Values are expressed as medians (interquartile ranges) or number (\%).
Table 4. AUC values of variables for the differentiation of viral meningitis and bacterial meningitis

\begin{tabular}{lc}
\hline Markers & AUC (95\% confidence interval) \\
\hline Delta neutrophil index $(\%)$ & $0.628(0.438-0.818)$ \\
White blood cell (cells/mL) & $0.687(0.512-0.862)$ \\
Neutrophil $(\%)$ & $0.657(0.453-0.861)$ \\
C-reactive protein $(\mathrm{mg} / \mathrm{dL})$ & $0.690(0.503-0.878)$ \\
\hline
\end{tabular}

AUC, area under curve.

Table 2. Inflammatory marker values in the two study groups

\begin{tabular}{lcc}
\hline Markers & Viral meningitis & Bacterial meningitis \\
\hline Delta neutrophil index $(\%)$ & $0.00(0.00-0.00)$ & $0.00(0.00-2.73)$ \\
White blood cells (cells/mL) & $7,385(6,133-10,485)$ & 0.057 \\
Neutrophils $(\%)$ & $73.7(61.6-80.1)$ & 0.034 \\
C-reactive protein $(\mathrm{mg} / \mathrm{dL})$ & $0.29(0.29-0.79)$ & 0.079 \\
\hline
\end{tabular}

Values are medians (interquartile ranges).

Table 3. Multiple logistic regression findings regarding the use of variables for the differential diagnosis of viral meningitis and bacterial meningitis

\begin{tabular}{lccc}
\hline Markers & Odds ratio & 95\% confidence interval & P-value \\
\hline Delta neutrophil index $(\%)$ & 1.319 & $0.817-2.131$ & 0.257 \\
White blood cells $(\mathrm{cell} / \mathrm{s} / \mathrm{mL})$ & 1.000 & $1.000-1.000$ & 0.090 \\
Neutrophils $(\%)$ & 0.977 & $0.916-1.042$ & 0.478 \\
C-reactive protein $(\mathrm{mg} / \mathrm{dL})$ & 1.084 & $0.975-1.204$ & 0.135 \\
\hline
\end{tabular}

stimulating factors, glucocorticoid, or another immunosuppressant before study enrollment were excluded.

\section{Statistical analysis}

Statistical analyses were performed using IBM SPSS Statistics ver. 20 (IBM Corp., Armonk, NY, USA). Nominal data are presented as frequencies and percentages and continuous data as medians and interquartile ranges. The Mann-Whitney U-test was used to compare continuous variables, and then biomarkers with a P-value of $<0.1$ were entered into multiple logistic regression to investigate the abilities of serum DNI and other biomarkers (WBC and neutrophil counts and CRP level) to differentiate BM and VM. In addition, the area under the receiver operating characteristic (ROC) curve was used to determine to what extent serum DNI differentiated these two groups. P-values of $<0.05$ were considered statistically significant.

\section{RESULTS}

Of 117 consecutive patients considered for this study, 13 patients with tuberculosis and two patients with fungal meningitis were excluded. Of the 104 patients enrolled, 52 were male (50.0\%), and the overall median age was 32.0 years. Ninety-two patients were in the VM group and 12 patients were in the BM group (Table 1). In the BM group, the causative pathogens were Streptococcus pneumoniae, Escherichia coli, and Listeria monocytogenes.

The median serum DNI was not statistically significantly higher in the BM group than in the VM group (0 [interquartile range, $0 \%$ to $2.73 \%$ ] vs. 0 [interquartile range, $0 \%$ to $0 \%$ ], $P=0.057$ ), but the WBC counts and CRP levels were statistically significantly different between the VM and BM groups (Table 2).

To evaluate the usefulness of serum DNI in differentiating VM from $\mathrm{BM}$, we performed multiple logistic regression analysis and evaluated the area under the ROC curve. The odds ratio and 95\% confidence interval of serum DNI were 1.319 and 0.817-2.131, respectively, by multiple logistic regression $(P=0.257)$ (Table 3$)$, and the area under the ROC curve for serum DNI was 0.628 (Table 4).

\section{DISCUSSION}

When managing patients with acute meningitis in the ED, early diagnosis of the type of infection (bacterial or viral) has the greatest impact on the clinical course and treatment, and thus, a number of studies have been undertaken to determine the effectiveness of different tests for differentiating BM and VM. In these previous studies, various common laboratory variables, including 
standard CSF variables and inflammatory markers in peripheral blood, such as WBC count and/or CRP level were examined. ${ }^{18}$ The use of serum markers has merits, because only a small blood sample is required, which can be processed in 20 minutes, ${ }_{1}^{19,20}$ and because knowledge of serum inflammatory markers might improve the sensitivity of etiologic diagnoses ${ }^{6,7}$ However, no previous study has evaluated the diagnostic accuracy of serum DNI with respect to differentiating $\mathrm{BM}$ and VM.

Crossing the blood-brain barrier is a key step in the pathophysiology of meningitis and is more likely in the setting of high-grade bacteremia. ${ }^{21}$ Serum DNI values are elevated in the presence of bacterial infection because they reflect circulating immature granulocyte fractions..$^{9-11}$ In addition, serum DNI has been shown to predict mortality in cases of spontaneous bacterial peritonitis ${ }^{22}$ and to be a marker of disease severity in critically ill patients with sepsis. ${ }^{23}$ Therefore, we hypothesized that serum DNI might be increased in acute BM. However, although serum DNI was higher in the BM group than in the VM group, no statistically significant difference was found (Table 2). Furthermore, no evidence was obtained by ROC analysis that serum DNI aids in the differentiation of BM and VM (Table 4). However, we think that further study of this issue is required.

CRP is a plasma protein, and its concentration rises dramatically as a result of cytokine-mediated responses to most forms of tissue injury, infection, and inflammation, and thus, the serum CRP level is widely used in clinical practice as an objective index of disease activity. ${ }^{24}$ It has been reported that CRP levels and WBC counts can be used to differentiate bacterial and viral infections, especially meningitis infections: ${ }_{i}^{25}$ in the present study, however, like DNI, the predictive values of the CRP levels and WBC counts were not sufficiently high to differentiate BM from VM (Tables 3, 4). Indeed, CRP levels can occasionally be low in bacterial diseases, especially during the early stages, and high CRP levels have been reported in some cases of $\mathrm{VM}^{26}$

Several limitations of the present study warrant consideration. First, the study had a retrospective design and a relatively small sample size and was conducted at the emergency center of one hospital. Second, it should also be borne in mind that many patients who present at EDs in Korea have used antibiotics, because antibiotics are generally prescribed by primary care physicians to patients with a fever and headache. Inflammatory markers can be affected by co-ingestion of antibiotics. In our study, four patients (33.3\%) may have co-ingested antibiotics in the BM group. However, we could not investigate the type and dose of antibiotics because this was a chart review study. There was no difference between patients who had not used antibiotics and those who did with respect to DNI (0.4 [interquartile range, $0 \%$ to $2.73 \%$ ] vs. 0 [interquartile range, $0 \%$ to $3.15 \%$ ], $P=0.570$ ). Accordingly, to overcome the limitations, further prospective study will be needed.

In summary, this study provided no evidence to support the notion that serum DNI aids in the differentiation of acute BM from acute VM in the ED.

\section{CONFLICT OF INTEREST}

No potential conflict of interest relevant to this article was reported.

\section{REFERENCES}

1. van de Beek D, de Gans J, Tunkel AR, Wijdicks EF. Communityacquired bacterial meningitis in adults. N Engl J Med 2006; 354:44-53.

2. Schuchat $A$, Robinson $K$, Wenger JD, et al. Bacterial meningitis in the United States in 1995: Active Surveillance Team. N Engl J Med 1997;337:970-6.

3. Julian-Jimenez A, Flores Chacartegui M, Palomo de los Reyes MJ, Brea-Zubigaray S. Usefulness of procalcitonin and C-reactive protein in the acute meningitis in the emergency department. Neurologia 2013;28:189-90.

4. Huy NT, Thao NT, Diep DT, Kikuchi M, Zamora J, Hirayama K. Cerebrospinal fluid lactate concentration to distinguish bacterial from aseptic meningitis: a systemic review and metaanalysis. Crit Care 2010;14:R240.

5. Nigrovic LE, Kuppermann N, Malley R. Development and validation of a multivariable predictive model to distinguish bacterial from aseptic meningitis in children in the post-Haemophilus influenzae era. Pediatrics 2002;110:712-9.

6. Saez-Llorens $X$, McCracken GH Jr. Bacterial meningitis in children. Lancet 2003;361:2139-48.

7. Tunkel AR, Hartman BJ, Kaplan SL, et al. Practice guidelines for the management of bacterial meningitis. Clin Infect Dis 2004;39:1267-84.

8. Maxson S, Lewno MJ, Schutze GE. Clinical usefulness of cerebrospinal fluid bacterial antigen studies. J Pediatr 1994;125: 235-8.

9. Kratz A, Maloum K, O'Malley C, et al. Enumeration of nucleated red blood cells with the ADVIA 2120 Hematology System: an International Multicenter Clinical Trial. Lab Hematol 2006;12:63-70.

10. Harris $N$, Jou JM, Devoto $G$, et al. Performance evaluation of the ADVIA 2120 hematology analyzer: an international multicenter clinical trial. Lab Hematol 2005;11:62-70.

11. Harris N, Kunicka J, Kratz A. The ADVIA 2120 hematology sys- 
tem: flow cytometry-based analysis of blood and body fluids in the routine hematology laboratory. Lab Hematol 2005;11: 47-61.

12. Cornbleet PJ. Clinical utility of the band count. Clin Lab Med 2002;22:101-36.

13. Seebach JD, Morant R, Ruegg R, Seifert B, Fehr J. The diagnostic value of the neutrophil left shift in predicting inflammatory and infectious disease. Am J Clin Pathol 1997;107:582-91.

14. Ansari-Lari MA, Kickler TS, Borowitz MJ. Immature granulocyte measurement using the Sysmex XE-2100. Relationship to infection and sepsis. Am J Clin Pathol 2003;120:795-9.

15. Nigro KG, O'Riordan M, Molloy EJ, Walsh MC, Sandhaus LM. Performance of an automated immature granulocyte count as a predictor of neonatal sepsis. Am J Clin Pathol 2005;123: 618-24.

16. Spanos A, Harrell FE Jr, Durack DT. Differential diagnosis of acute meningitis. An analysis of the predictive value of initial observations. JAMA 1989;262:2700-7.

17. Nahm $\mathrm{CH}$, Choi JW, Lee J. Delta neutrophil index in automated immature granulocyte counts for assessing disease severity of patients with sepsis. Ann Clin Lab Sci 2008;38:241-6.

18. Tatara $\mathrm{R}$, Imai $H$. Serum C-reactive protein in the differential diagnosis of childhood meningitis. Pediatr Int 2000;42:541-6.

19. del Estal PL. Meningitis associated with spinal anaesthesia: not always bacterial. Neurologia $2011 ; 26: 442-3$.
20. Jimenez AJ, de los Reyes MJ, Diaz-Miguel RO, Guerrero AP, Miguez RP, Martinez RS. Utility of procalcitonin and C-reactive protein in the septic patient in the emergency department. Emergencias 2009;21:23-7.

21. Putz K, Hayani K, Zar FA. Meningitis. Prim Care 2013;40:70726.

22. Lim TS, Kim BK, Lee JW, et al. Use of the delta neutrophil index as a prognostic factor of mortality in patients with spontaneous bacterial peritonitis: implications of a simple and useful marker. PLoS One 2014;9:e86884.

23. Park BH, Kang YA, Park MS, et al. Delta neutrophil index as an early marker of disease severity in critically ill patients with sepsis. BMC Infect Dis 2011;11:299.

24. Pepys MB. The acute phase response and C-reactive protein. In: Warrell DA, Cox TM, Firth JD, editors. Oxford textbook of medicine. 5th ed. Oxford: Oxford University Press; 1995. p.152733.

25. Hatherill M, Tibby SM, Sykes K, Turner C, Murdoch IA. Diagnostic markers of infection: comparison of procalcitonin with $C$ reactive protein and leucocyte count. Arch Dis Child 1999; 81:417-21.

26. Hansson LO, Axelsson G, Linne T, Aurelius E, Lindquist L. Serum $\mathrm{C}$-reactive protein in the differential diagnosis of acute meningitis. Scand J Infect Dis 1993;25:625-30. 